\title{
Philosophers are doing something different now: Quantitative data
}

\author{
Joshua Knobe* \\ Program in Cognitive Science and Department of Philosophy, Yale University, United States
}

\section{A R T I C L E I N F O}

\section{Article history:}

Available online 28 November 2014

\section{Keywords:}

Philosophy of mind

Philosophy of cognitive science

Bibliometrics

\begin{abstract}
A B S T R A C T
The philosophical study of mind in the twentieth century was dominated by a research program that used a priori methods to address foundational questions. Since that time, however, the philosophical study of mind has undergone a dramatic shift. To provide a more accurate picture of contemporary philosophical work, I compared a sample of highly cited philosophy papers from the past five years with a sample of highly cited philosophy papers from the twentieth century. In the twentieth century sample, the majority of papers used purely a priori methods, while only a minority cited results from empirical studies. In the sample from the past five years, the methodology is radically different. The majority of papers cite results from empirical studies, a sizable proportion report original experimental results, and only a small minority are purely a priori. Overall, the results of the review suggest that the philosophical study of mind has become considerably more integrated into the broader interdisciplinary field of cognitive science.
\end{abstract}

(c) 2014 Elsevier B.V. All rights reserved.

\section{Introduction}

The twentieth century saw the rise of a quite specific approach to the philosophical study of mind. It would be difficult to spell out explicitly all of the elements that defined this approach, but at the very minimum, it seems that it was characterized by the following two features:

(1a) The philosophical study of mind was not supposed to rely on the results of empirical studies. It was supposed to proceed through a priori reasoning.

(1b) The philosophical study of mind was not supposed to be concerned with questions about the workings of specific cognitive processes. It was supposed to be concerned with more distinctively philosophical questions regarding the metaphysics of mind (the mind-body problem, the nature of content, etc.).

\footnotetext{
* Address: Department of Philosophy, Yale University, P.O. Box 208306 New Haven, CT 06520-8306, United States.

E-mail address: joshua.knobe@yale.edu
}

Because this research program was so influential at the time, it has done a lot to shape the perception of philosophy within the broader cognitive science community. Many cognitive scientists probably assume that contemporary philosophical research is still continuing within that same basic paradigm. In actual fact, however, nothing could be further from the case. Over the past few decades, the philosophical study of mind has undergone a rather dramatic shift. There has been a stark decrease in interest in the approach that dominated the philosophical study of mind in the twentieth century and a corresponding increase in interest in a very different sort of approach. More specifically:

(2a) At this point, the vast majority of papers in the philosophical study of mind engage in some way with the results of empirical studies.

(2b) The field is no longer dominated by research on metaphysical questions. Instead, the majority of papers are concerned with questions about the workings of specific cognitive processes (social cognition, causal cognition, moral cognition, etc.). 
I worry that many cognitive scientists may not be aware of just how radically philosophical work on the mind has changed. It therefore seemed helpful to provide some quantitative data.

\section{Quantitative review: Highly cited papers in philosophy journals, 1960-1999 vs. 2009-2013}

To do this, I turned to the entry on 'Philosophy' in Google Scholar Metrics. This source lists the twenty most highly cited philosophy journals from the past five years (2009-2013) and, within each of those journals, the most highly cited papers. In total, the list comprises 397 papers.

Then, to compare these papers with a sample of twentieth century work, I took the list of journals from Google Scholar Metrics, entered it into Web of Science and picked the 397 most highly cited papers from those journals from a period in the twentieth century (1960-1999). In other words, I gathered two samples of philosophy papers, consisting of highly cited papers from the same list of journals but at two different time periods.

The review was conducted by coding these papers into categories and then comparing results for the two time periods. Inevitably, such coding will involve a certain amount of subjective judgment, and other researchers might reasonably have decided to include this or that specific paper in a different category. Nonetheless, my sense was that a quantitative approach like this one could provide far more information than could be obtained from a purely qualitative review. (The entire list of papers and their codes appears in Supplementary Materials.)

I began by selecting the subset of papers that were concerned with questions about the mind. This subset included papers pursuing traditional sorts of questions in the philosophy of mind, papers concerned with questions in the philosophy of cognitive science, and also papers that reported original psychological studies. The subset contained a total of 85 twentieth century papers and 157 contemporary papers.

\subsection{Frequencies of methods}

I first coded each paper for the method it employed. ${ }^{1}$ Specifically, I coded the papers into three categories:

(a) Those that use only a priori reasoning and do not rely on results of empirical studies.

(b) Those that actually report original empirical results.

(c) Those that do not report original empirical results but do rely on the results of empirical studies published elsewhere.

Before reading onward, it might be helpful to make a guess about the relative size of the first two categories within contemporary research. So try taking a guess: are

\footnotetext{
1 Because this particular coding was so central to the present argument, I asked a research assistant to code a randomly selected subset of the papers (comprising 50 of the 157 contemporary papers). Interrater reliability was $92 \%, \kappa=.85$.
}

there more papers that rely solely on a priori reasoning, or are there more that report the results of experiments conducted by philosophers?

First, let's consider the papers from the twentieth century sample. It turns out that the majority of these papers (62.4\%) are purely a priori, with a minority (37.6\%) relying on existing empirical research and none at all (0\%) reporting original experimental results. This first result should come as no surprise. It simply reflects the well-known focus of twentieth century research in the philosophical study of mind.

But now suppose we turn to the contemporary papers. There we find a completely different distribution. The majority of papers (61.8\%) rely on empirical research, a substantial proportion (26.8\%) report original experimental results, and only a small minority (11.5\%) are purely a priori.

Of course, one might worry that the method employed here provides a picture of the field that is biased in one direction or another. For this reason, one might reasonably be reluctant to use this method to arrive at any definite conclusions regarding the type of research being conducted in any given time period. Still, it does seem that this method can provide helpful information about the difference between time periods. We are looking at highly cited papers within the same set of journals at two different time periods, and if we find a difference between the two, we thereby acquire strong reason to conclude that something important within philosophical practice has changed.

As Fig. 1 shows, the difference observed in this dataset is surprisingly substantial. The majority of the twentieth century papers used purely a priori methods, whereas this approach appears only in a small minority of the contemporary papers. Conversely, there were no papers at all in the twentieth century sample that reported original experimental results, but original experimental results actually appear in a sizeable proportion of the contemporary sample.

\subsection{Frequencies of topics}

I then categorized each paper in terms of the topic it took up. The full list of papers and topics can be found in Supplementary Materials. To provide a summary here, I list all topics represented by more than one paper.

For the twentieth century papers, the distribution of topics was as follows:

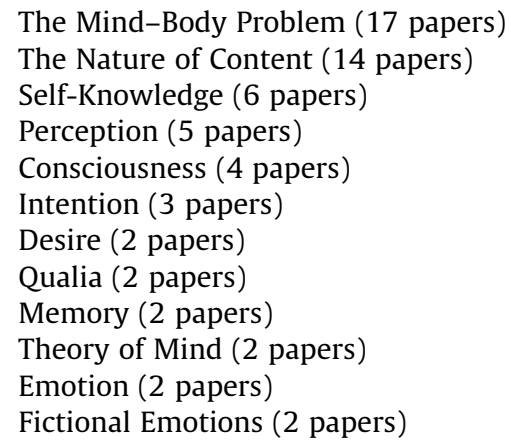



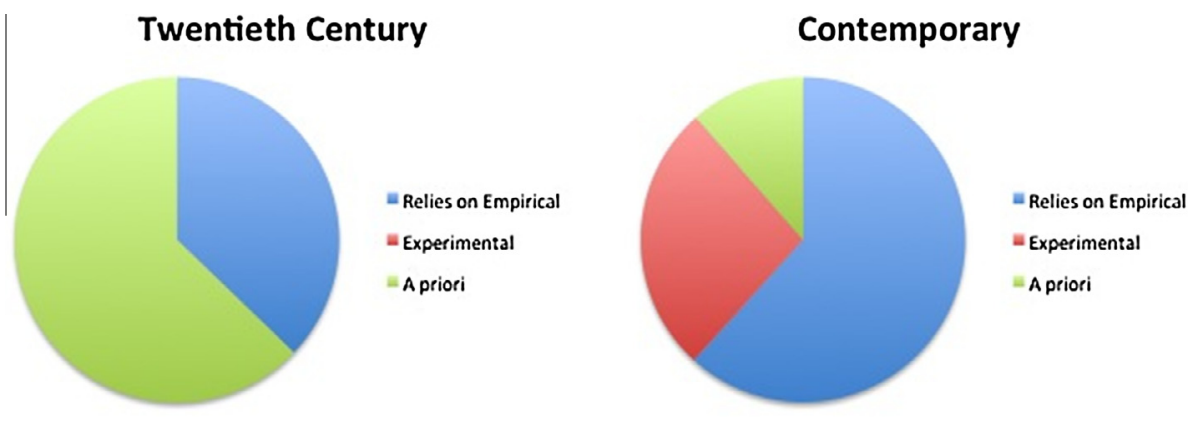

Fig. 1. Highly cited papers by method in a sample of twentieth century papers vs. in a sample of contemporary papers.

Aficionados of philosophy will recognize many of these topics as aspects of a closely related set of issues in the metaphysics of mind.

The distribution of topics in the contemporary papers, however, is radically different:

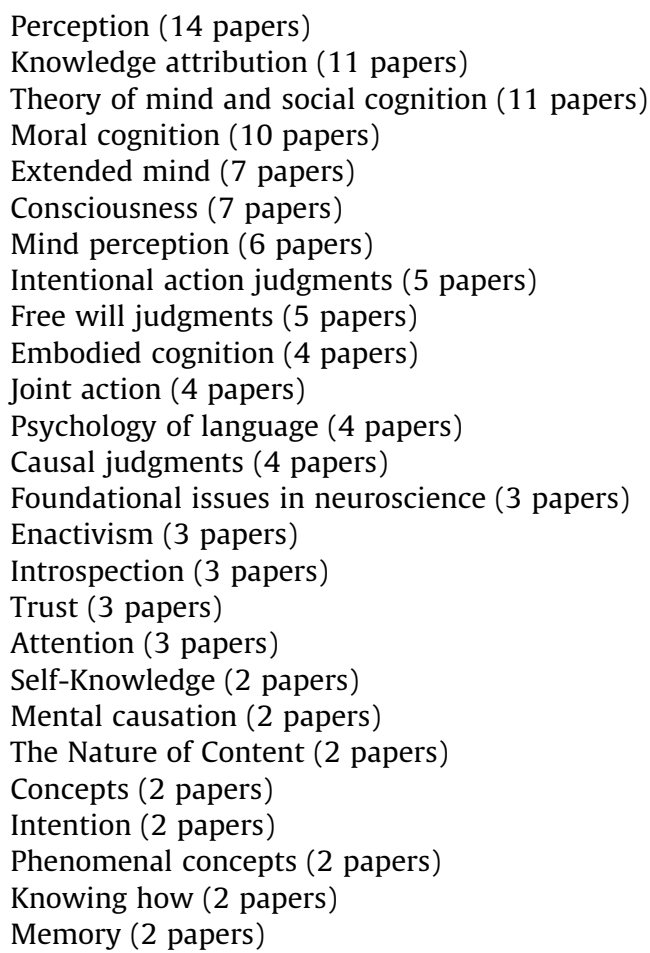

The first thing to notice here is the rather spectacular decline in interest in the topics that dominated twentieth century research in the philosophical study of mind. At this point, there are hardly any papers on the mind-body problem, the nature of content, or any other topics in the metaphysics of mind.

The second thing to notice is the rise of a very different sort of research program. Contemporary papers in the philosophical study of mind are concerned primarily with the attempt to investigate specific aspects of cognition. They tend not to be aimed at addressing metaphysical questions but instead to be engaged in an effort to use systematic empirical data to gain a better understanding of how these aspects of cognition actually work.

More specifically, there has been a surge of research looking in detail at the cognitive processes that give rise to people's judgments about philosophically relevant matters (morality, knowledge, causation, etc.). If we consider all topics that fall within this general research program, including those represented only by a single paper, we find 45 papers in total. Thus, this program has a fair claim to be considered the dominant one in the contemporary philosophical study of mind.

\section{Discussion}

The present review compared highly cited papers in the philosophical study of mind from a contemporary period (2009-2013) with papers from the twentieth century (1960-1999). The two periods differed both in method and in topic. In method, one finds a strong shift toward the use of systematic empirical data, including original experiments conducted by philosophers. In topic, one finds a shift toward the exploration of specific aspects of cognition.

Clearly, these two shifts are quite closely related. Both reflect the degree to which the philosophical study of mind has become integrated within the interdisciplinary field of cognitive science. There appears to be an emerging consensus that philosophers do not necessarily need to develop special methods or topics that set them apart from researchers in other disciplines. Instead, philosophers are becoming increasingly engaged with the methods and topics that characterize this broader interdisciplinary field.

\section{Author note}

I am grateful for comments from Aaron Norby, Brian Scholl, Ike Silver, and one anonymous reviewer.

\section{Appendix A. Supplementary data}

Supplementary data associated with this article can be found, in the online version, at http://dx.doi.org/10.1016/ j.cognition.2014.11.011. 